\title{
Bimanual response asymmetry as an indicator of speech dysfunction
}

\author{
EDWARD H. BOGART \\ College of William and Mary, Williamsburg, Virginia 23185
}

\begin{abstract}
Poor spellers and good spellers were tested to see if specific verbal disabilities were associated with anomalous patterns of cerebral dominance. Hemispheric dominance for speech was assessed by latency for recognition of unilaterally presented letter pairs. Poor spellers did not differ from good spellers in patterns of cerebral dominance, but they had longer latencies when responding with the preferred (right) hand than with the left hand, or than the good spellers with either hand.
\end{abstract}

Sensation and motor control for any area of the body have been attributed to the contralateral cerebral cortex (Mountcastle, 1962). The control of speech functions has been associated with the dominant hemisphere of the brain, the hemisphere contralateral to the preferred hand (White, 1969). Orton (1928) concluded that some speech defects were caused by improperly developed patterns of dominance and handedness. He found numerous cases in which specific verbal dysfunctions were accompanied by incomplete development of handedness or indications of anomalous development of cerebral dominance. From this it was hypothesized that persons who demonstrate specific verbal dysfunctions would also show dominance anomalies. It was predicted that if subjects with verbal dysfunction and normal subjects were tested for locus of speech control in the cerebral cortex, the two groups would differ in that the normal group would show indication of speech control in the left hemisphere while the verbal dysfunction group would show diffuse control.

In the present study, poor spelling ability was selected as the specific verbal dysfunction because it is easy to diagnose, and it occurs with reasonable frequency in a college population. The method followed Egeth and Epstein (1972) and was based on the theory that the verbal hemisphere of the brain is specialized for judgments of "same," and the nonverbal hemisphere is specialized for judgments of "different." Thus, judgment of a pair of letters, both identical, presented in the right visual field (RVF) should be faster than if they were presented to the left visual field (LVF), because the projection of the RVF is solely to the left hemisphere. Most researchers (Duane, Note 1) have found a clear RVF superiority for "same" stimulus pairs and a LVF superiority for "different" stimulus pairs.

\section{METHOD}

A total of 12 subjects took part in this experiment, six male and six female. All subjects were drawn from the population of the College of William and Mary in Virginia (undergraduate and graduate students and faculty). The subjects in the experimental group were selected on the basis of self-reported poor spelling. The control group was made up of self-reported good spellers.
The stimuii were pairs of ietters arranged one above the other and separated by a distance that subtended a visual angle of about $3 \mathrm{deg}$ when viewed from the standard viewing distance of $30 \mathrm{~cm}$. Each pair was located either to the left or to the right of fixation, a distance that subtended a visual angle of $5 \mathrm{deg}$. Stimuli consisted of 18 point future bold dry transfer letters, A, $\mathrm{I}, \mathrm{O}, \mathrm{U}, \mathrm{X}, \mathrm{V}$, and $\mathrm{Y}$, the same as those used by Egeth and Epstein (1972).

There were a total of 80 stimulus pairs, 40 located to the left of fixation. In half the stimulus pairs, the letters were the same and in half they were different. Each of the six stimulus letters appeared the same number of times in each of the four letter positions and the same number of times in "same" pairs and "different" pairs. This meant that of the 80 stimulus pairs, 20 were right-same, 20 were left-same, 20 were right-different, and 20 were left-different.

Stimuli were presented using a Lafayette one-channel tachistoscope (Model 2500) modified so that it would trigger a Hunter timer (Model 120a). A bidirectional response key was connected to stop the timer and indicate the subject's response choice.

At the beginning of the initial session, each subject was told in detail about the design of the experiment and the experimental hypothesis. Each subject was allowed as many practice trials as desired to become proficient at responding.

At the beginning of each trial, the stimulus cards were randomized by shuffling. The 80 stimulus pairs were presented one at a time at a rate of about four/min, and the subject responded by means of the hand key as to whether he perceived the letters as same or different. Latency of response was recorded for each stimulus pair, and errors in same-different judgments were recorded.

All 12 subjects were tested at least once responding with the left hand and once with the right hand. Most subjects were tested more than once with each hand to determine test-retest reliability.

\section{RESULTS}

Mean reaction times for both groups of subjects for all combinations of response hand, "same" or "different" stimulus pair, and visual hemifield are presented in Table 1.

The results replicate the other studies on unilateral same-different reaction time, especially Egeth and Epstein (1972). There is a clear RVF superiority for "same" judgments for both groups using either hand $\mathrm{F}(1,10)=8.28, \mathrm{p}<.05$.

Visual field superiority did not differentiate between good and poor spellers as was predicted. Since visual 
Table 1

Mean Response Latencies in Seconds

\begin{tabular}{|c|c|c|c|c|c|c|c|c|}
\hline & \multicolumn{4}{|c|}{ Right-Hand Responses } & \multicolumn{4}{|c|}{ Left-Hand Responses } \\
\hline & \multicolumn{2}{|c|}{ Same } & \multicolumn{2}{|c|}{ Different } & \multicolumn{2}{|c|}{ Same } & \multicolumn{2}{|c|}{ Different } \\
\hline & LVF & RVF & LVF & RVF & LVF & RVF & LVF & RVF \\
\hline $\begin{array}{l}\text { Experimental Group } \\
\text { Grand Mean }\end{array}$ & \multicolumn{4}{|c|}{1.047} & .750 & \multicolumn{2}{|c|}{.707} & .719 \\
\hline $\begin{array}{l}\text { Control Group } \\
\text { Grand Mean }\end{array}$ & \multicolumn{3}{|c|}{.593} & .595 & .626 & .593 & .577 & .564 \\
\hline
\end{tabular}

field superiority was used to indicate cerebral dominance, it must be concluded that the poor spellers do not evidence anomalous patterns of dominance and the hypothesis is disconfirmed.

Another, unexpected, effect was found that did differentiate between poor and good spellers. The mean latency for the poor spellers' right hand responding $(\overline{\mathrm{X}}=1.047 \mathrm{sec})$ was $.340 \mathrm{sec}$ slower than their left hand responding and $.455 \mathrm{sec}$ slower than the responses of the good spellers using either hand. Both differences are significant, $\mathrm{p}<.01$, by a Newman-Keuls test. Consequently, the interaction of group and response had was highly significant, $F(1,10)=45.66, p<.01$.

\section{DISCUSSION}

Although these results do not support Orton's theory of speech dysfunction, they do fit the theory of specific encoding of memory of Fernald (1943). She stated that each person encodes memories in one of three modes; as verbal traces, visual images, or as kinesthetic patterns, and that kinesthetic encoding is inefficient for verbal storage so kinesthetic encoders will show verbal deficits.

If so, the long latencies of the poor spellers are a result of interference due to simultaneous processing of two kinesthetic tasks; the judgment of the kinesthetic memory trace of the stimulus pair and the kinesthetically encoded response of moving the hand key. This effect is accentuated for right-handed responses since the cortical area associated with motor control of the right hand and the area associated with verbal memory tend to overlap (Penfield \& Roberts, 1959).

\section{REFERENCE NOTE}

1. Duane, D. D. The relationship of language learning and the brain. Paper presented at the 24th annual conference of the Orton Society, Baltimore, Maryland, November, 1973.

\section{REFERENCES}

Egeth, H., \& Epstein, J. Different specialization of the cerebral hemisphere for the perception of sameness and difference. Perception and Psy chophysics, 1972, 12, 218-220.

Fernald, G. M. Remedial techniques in basic school subjects. New York: McGraw-Hill, 1943.

Mountcastle, V. S. Interhemispheric relations and cerebral dominance. Baltimore: Johns Hopkins Press, 1962.

Orton, S. T. Specific reading disability-Strephosymbolia. Journal of the American Medical Association, 1928, 90, 1094-1099.

Penfield, W., \& Roberts, L. Speech and brain mechanism. Princeton, N. J: Princeton University Press, 1959.

White, M. J. Laterality differences in perception: A review. Psychological Bulletin, 1969, 72, 387-405.

(Received for publication March 3, 1975.) 